\title{
REVIEW A COMMON APPROACH IN THE ANALYSIS OF IRANIAN PAINTING IN REFERENCE TO CRITICISM OF DECONSTRUCTION
}

\author{
Z. Jafarzadeh \\ MA, University of Tehran, non-profit Rassam lecturer and Islamic Azad University of \\ Parand
}

Published online: 15 February 2017

\begin{abstract}
This study is aimed in presenting case criticism of 3 articles, which are representatives of wide range of studies conducted in field of Iranian art and painting in view of author and is also aimed in presenting the fundamental weakness of these studies in proving their claims and challenge language used in them. As the feature and the goal of using this language is the foundation of certain differentiation of western art and Iranian painting and dual concepts such as light and darkness, two-dimensional and three-dimensional, material and spiritual concepts are considered, the deconstructive criticism could be useful. Particularly, due to the criticism applied by post-structuralism critics like Paul De Man based on same concepts on west art tradition, the question is that on which language the definite differentiation of west and east art (Iranian painting and Western painting tradition) and considering origin for one of them is realized and whether is this language a research, perfect, fair, universal and reliable language or not? The assumption is that it seems that the language used in some analyses on Iranian painting trying to determine completely different and higher position of Iranian painting is a general and reliable language on basis on dual concepts that their definite differentiation is doubted in view of deconstructive critic. As the analytical language used by Iranian scholars is similar to language challenged in West culture and art by themselves, the definite differentiation and superiority considered between Iranian and Western art could be doubted and questioned.
\end{abstract}

Key words: criticism, analysis, Iranian painting, deconstructive criticism

Author Correspondence, e-mail: author@yahoo.com

doi: http://dx.doi.org/10.4314/jfas.v9i1s.711 


\section{INTRODUCTION}

One solution selected by critics and scholars and professors of field of art in Iran to determine different identity for Iranian painting is showing the contrast between Iranian painting and Western painting art. In some analyses, an attitude could be observed that consider western painting in a general form and free from contradictions and diversity and describe it using features such as materiality, human-orientation and sensual features and try to show its fundamental difference with Iranian paining. In this regard, dual concepts such as light and darkness, abstraction-spirituality against figurative-materiality, two-dimensional-imagine and three-dimensional-worldly concepts play key role. Most of these analyses tend to explain the superior position of Iranian art compared to Western art. An example of using such language is a study conducted by Ayatollahi:

"In west, a culture and art is deformed that its destiny is in Egypt and its origins are in Greece and Rome and it believes that perfection is in realism, human-orientation, denudation and material and worldly pleasures as the abstract form of the civilization of ancient Rome. However, Islamic art (Islamic Iran art) has its origins in the culture of Mazdean monotheism of Achaemenids and Sassanids and its destiny is Sumer and Ancient Ilam and considers perfection in going beyond the realities, the material world and time and place and achievement to the reality of events and things at a world without time and place and in contact with the space beyond materiality and humanity" (Ayatollahi, 2009, 37-38). According to this attitude, the essence of West Art is a unit element with physical deformation. There are many or even countless examples in this field.

Deconstructive criticism ${ }^{1}$ reached its peak in $70 \mathrm{~s}$ decade based on attitudes and ideas of Jacques Derrida (1930-1998), French Philosopher and has considered the criticism of Western-European culture and art and history and has indicated that how western thought is formed based on concepts of light and darkness in field of art in imagination and fancy and has preferred one concept to another based on "Heliocentrism" attitude according to Derrida. Deconstructive criticism tends to show that proving the definite differentiation of these dual contrasts is impossible in linguistic uses and in their metaphorical results. Hence, according to the author, this reading method could help people to discover the similarities and the approximation of cultures and creation of more democratic discourse. In this field, it should be noted that according to this attitude that language is basically a metaphysical issue, Derrida

\footnotetext{
${ }^{1}$ Deconstruction: $\mathrm{t}$ is a form of textual analysis, which is usually along with revision of forms, structures and content of works. The deconstruction approach in art criticism denies any kind of differentiation of superior and inferior and low-high forms (Nozari, 2007, 71-72).
} 
has no tendency to leave the metaphysics caused by this language ${ }^{2}$. Peter Sedgwick says: "any kind of critical response to this metaphysics could not itself lead to explanation of the lean ontology searched by thinkers such as Deleuze; In other words, someone who has no tendency to leave metaphysics. This is right; although people should tend to achieve freedom from the metaphysics. However, freedom from the metaphysics can't mean that people have entered to a line of thinking that leads them beyond the metaphysics, since this is meaningless and can deprive people from light of meaning and semantics" (Sedgwick, 2009, 304-305).

Hence, the intention here is not criticizing the metaphysics to destroy it, but also the trend is to show the weakness of claims of the language formed it. Paul De man (1919-83) has challenged non-lingual concepts assumed in this attitude through criticizing the concept of supernatural-imagine imagination and fact-finding concept considered by romantic poets. It seems that Iranian artists at least use same language criticized and challenged by Western critic in western culture in realm of analytical language to determine different identity of Iranian art from Western art.

The deconstructive criticism of the analytical language of Iranian art experts can challenge the absolute differentiation and superiority of art and culture and art of a nation to art and culture of another nation in benefit of an non-ideological and democratic attitude and to approximate artists and art of east and west nations and presents the restrictions of the said traditional language in analysis and criticism of artistic works.

In this study, two subjects are considered in line with each other. The first subject is deconstructive criticism and the attitudes in it that are discussed in short and in limit of this study. However, in this study, the first subject is considered. Second section is an overview of language of discussed papers and the author believes that a part of the common language is analysis of ancient art and painting of Iran. The second section is mostly followed in the main body of the article. As a part of this research is careful study of discussed proses, several proses have been presented that have encompassed the analyzed elements of language emphasized in this study in view of the author and the dispersion of subjects is avoided. The method used in this study is descriptive-critical method based on library sources.

\footnotetext{
${ }^{2}$ Nojumian has conducted a study under the title of "Derrida and lingual paradoxes in literature" and has said: "language has been always considered as a criterion for the metaphysics theory, since the lingual system has been basically founded on the basis of metaphysics laws" (Nojumian, 2007, 224).
} 
Here, the research significance is presented in short. Apparently, the official and academic language of artistic analysis of Iranian art, especially about the traditional works of Iranian painting and those who take content criticism of these works, has faced a kind of stagnation and repetition. In lots of these critical proses, similar patterns have been used to analyze the content and form of these works repetitively and the details, case study and prove of ideas and beliefs are rarely considered. Maybe this is because this language has been changed into common language of analysis of Iranian old works and believes that there is no force to revise the presumptions and prove the claims. Deconstructive criticism tends to show non-academic and metaphorical identity of fields of knowledge that separate themselves to preserve the apparently special structure and language: the growth of something recognized under the title of academic fields is an underlying feature of a historical process, through which a series of inferential fields have become independent more and less, so that the literary realities have been determined just based on literary-critical criteria with the ability to specify reality (Webster, 2007, 251, 252). The said analytical attitude to old works of Iranian art, according to the author, could lead to a fraction and gap between critics considering contemporary art of Iran and world and critics analyzing old art and closing the way of useful discourse of past and present time through giving originality to a historical period and artistic type. Moreover, a language is created that has no tendency to prove its claims after a while and expresses a series of fixed ideas and examples with such thinking in parallel way. Such language can also lead to a kind of false disposal in people with no deep encounter with the Iranian traditional art and they may lose the opportunity to enjoy and think about these works.

The author believes that even without emphasizing generality of ideas and worldview of deconstructive critics, the deconstructive criticism style could be applied to break the strict and non-dynamic space of and the ways could be paved for more democratic discourse about precious Iranian artistic works with the new generation and also other cultures.

\section{A review of history (deconstructive criticism)}

Derrida, the French Philosopher and Deconstructive Critic, has referred to a special concept called "force" in his discussion on language: "the constructive model, while clearing the structural and visual element for us, hides the force causing such transparency from our looks" (Sedgwick, 2009, 300). Hence, the said force is the context of meaning and structure that is hidden from eyes. Derrida explains that how such hiding and veiling makes constructivism exposed to risk of belonging to appearance and sophistry existing in it 
metaphorically (ibid, 302). Such belonging to sophistry is something that hides the force from eyes. Beyond the sophistry, an effort is existed to prove the meaning in form and structure that leads to West thinking tradition according to Derrida:

"Structural metaphor pays special attention to role of imagination in thinking. Derrida believes that western tradition Representational perception of idea; thinking as imagination and as equality of imagination with the reality. Here, a kind of conceptualization is existed with trend to neglect the issue of force" (ibid, 303).

This attitude is a representation of the most underlying pillars of language that is going to be criticized; a language that considers color, form and script as the manifestation of the spiritualistic world of imagination and uses a rhythm that tends to neglect uncontrollable and sophistic aspects: "it is a gap between the reality and the way collapsing the context and structure of the claim as apparently rational issue" (Norris, 2003, 106). The main problem with the language is that it fails to explain the gap between image and the content hidden in the image. It means the image is unable to explain the allegorical issue in materialistic from based on a research language. Moreover, it considers the language as means to make value for an artistic manifestation (e.g. Iranian painting in this study) and ignoring the value of other arts.

The criticism of this representational thinking has its root in ideas of Ferdinand de Saussure (1857-1913), Swiss Linguist ${ }^{3}$. He believed that language is a network of meanings based on difference. There is no one-by-one and self-cleared relationship between cause and effect a word (written or oral) as sign and concept transferred by the word (ibid, 24). In heart of such thinking, the Western thinker always tends to find a center for explanation of a unit concept; a center that is assumed always out of the structure and a center that guarantees the cause and effect. Derrida says: "hence, it has been always imagined that the center, which is unit based on definition, forms that part of structure that escapes from structuralism at the same time that it monitors the structure" (Derrida, 2000, 90) ${ }^{4}$.

In same field of proving the meaning, it could be observed that in dual contrasts such as light and darkness, sky and earth, body and soul; how one party as the akin of the center traditionally is preferred and is considered as cause to represent the reality. This is the event that the author in this study tends to discuss on language of the studied articles.

\footnotetext{
${ }^{3}$ Derrida rejects the dual contrasts dominated on structure of language considered by Saussure as the basis for semiotic analyses and says that the contrast is rooted in Western Metaphysics (Zamiran, 2007, 86-87).

"Thus it has always been thought that the center, which is by definition unique, constituted that very thing within a structure which while governing the structure escapes structuralism."
} 
Deconstruction questions non-structural nature of center and its freeness from metaphorical image-spatial game explaining it. The language is rooted in solar metaphysics according to Derrida: "it means the metaphysics, in which the power is collapsed as a result of power of represented image, at which the intensity of light can result in priority of the representation" (Sedgwick, 2009, 304). In continue, Sedgwick explains that solar metaphysics could provide metaphysic on-all-environments. It means that the solar metaphysics provides a description of reality as logics and rationality provided to velar the field of existence (ibid). The reality has no unity and is same center; a center assumed out of the structure. The language of lightdarkness metaphor is also one of the most underlying types used abundantly in field of Iranian art and painting. As a result of differentiating the form clearing holy issue and form raised just from ambiguous game, the imagination of the painter is assumed something other than imagination of paranoid artist. Paul De Man, the poststructuralist critic has criticized romantic poets and has considered their imagination as a concept out of the world of inferences and could express such illuminative reality through this, which is non-expressible. In explanation of such imagination, it should be mentioned that ST Coleridge, English Poet and Critic, believes that imagination is different from fancy, which could be changed: on the contrary, the imagination shows itself in balance of contrasts or disparate qualities and in reconciliation of difference and similarity, overall and partial, idea and image, etc. (Coleridge, 1981, 230, 231)

Hence, imagination is a factor, in light of which the symbol become same with the idea or reality and the gap between them is removed or the force is collapsed in its light according to Derrida. De Man tries to demonstrate that such imagination separated from and beyond the structures of lingual inferences of mind of the poet is unexplainable. The imagination of Iranian artist and painter has been described in same way in many cases; meaning the power picking the gap between form and the world of imagination and instance. All mentioned above could be supervision on large branch of western thought with trend to discover language and image as the manifestation of the reality be the mediation of a reality out of the structure. There was no criticism like this, unless with regard to this issue that the claim for such reality has been existed in Western culture and thought. Rudolf Otto, in his book "Sacred", says: sacred contains a completely different element separating it from a rational concept and changing it to a concept that removes conceptual perception absolutely. Same issue is true for the field of beauty and aesthetics (as different range of human experience) (Rudolf, 2001, 45). Such attitude is nothing created by human mind and thought, but also Otto 
believes that roots of the superior concept are in analysis of West and east history and believes that one of its manifestations could be found in art and architecture ${ }^{5}$.

Hence, it is clear that a part of West art has tended to manifest the sacred beyond the description, which its roots and thinking backgrounds are criticized by poststructuralist critics like De Man.

It should be mentioned that the aim by expressing this issue is not to find the similarity; meaning that the similar components in two cultures and their thinking origins, since the issue here is formal manifestation of sacred, realty and imagination that has been always considered beyond explanation and description. Hence, how one of assumptive manifestations could be preferred to other one (however, the nature of the reality is an issue beyond the time, place and language)? For example, how "2-dimensional" could be considered as one manifestation of the imagined light that is not natural light in a contradictory expression? It means that one has claimed once that the 2-D (without highlight) is supernatural and non-material and the bed for manifestation of light and say once again that this light is not relevant to highlight and natural light. Such language may be explainable in position of talking about an irrational issue; although it seems unacceptable in position of language claiming for inference and expanding its results to the limit of originality and preference of an artistic tradition to assumed generality of another culture and history.

\section{Analysis of literature}

In the study "Iranian painting, manifestation of Kingdom of Imagination", the authors claim that Iranian painting is the scene of emergence and display of kingdom of imagination, which has been proved by Sohrevardi using different rational, transferred and scout reasons and has explained different phenomena in its light (Eskandarpour Khorami and Shafiei, 2011, 19). In field of explanation of the world of imagination, according to Hussein Nasr, it has been mentioned that the imaginative world could make the painter be aware of the world beyond the physical world, but with special time and place and forms; a world, at which events happen but not in materialistic form (quoted from Nasr, ibid). Hence, the world of painting is a non-physical world but with time and place. Here, the question is that how is the nonphysical world with time and place? Later in this study, it has been mentioned that space in painting is considered as a form that the viewer sees the painting beyond time and place and

\footnotetext{
${ }^{5}$ Refer to concept of sacred, p.138
} 
on top of the nature and as a supervisor on the events and phenomena of the world (ibid) ${ }^{6}$. Hence, once the theory is considered that painting is the image of a world with time and place and once the theory is rejected. It could be imagined that the aim by time and place in the first statement is imagined time and place and is different from material time and place. This type of paradoxes forcing people adding imaginative or imagined adjective to concepts such as time and place could be one of the features of the desired language. In explanation of a painting of Merajnameh, the authors have said: "the world of imagination is a light world with lightened forms $[\ldots]$ and [also dark forms $]^{7}[\ldots]$. The darkness should not be considered same as natural light, along with which highlight is considered" (ibid). Hence, there is darkness that could not be discriminated with regard to absence of natural light. Once again, concepts such as imagined light should be considered ${ }^{8}$.

In regard with discrimination of religious art, the authors of this study have mentioned that this art is "Symbol of Divide Forms" (ibid, 24) and believe that the foundations of art are present at the world of souls according to Dinani (ibid). Also, they have found that undoubtedly, if the visual space of a painting is declined to a 3-D quality, it has been declined to an image of world of angels and without transcendental meanings (ibid, quoted from Jalal Kamali). Hence, apparently, one quality of painting to display the imagined light is its 2-D nature. However, 2-D in this discourse is defined with absence of contrast (material light and depth). Hence, it is a material quality. In fact, colors have been abstracted from abstract and light properties of same luminous properties of same light world [world of imagination]. In other words, colors reflected on painting screen are different levels of light and in each level, they have been appeared for the wayfarer artist and are manifested in the imagination of the painter and have changed the painting story to the symbolic picture of manifestation of the realities of the world of light (ibid, 25).

The natural light is imagined as a symbol of divine Light and the artist should consider it as natural light and a symbol of it to explain the quality of that divine light. Hence, the unknown light has been explained just from this perspective that is light and not from that perspective that is divine and non-material. In fact, this is nothing said more than "light is light".

\footnotetext{
${ }^{6}$ It should be noted that here the author has referred to general viewpoint of the viewer while watching the painting and it seems that the viewer is watching it from the top point. Such point of view is a physical situation interpreted as looking beyond time and place.

${ }^{7}$ Writing mistake

${ }^{8} \mathrm{John}$ Cage, in his book "Color in Art", has found a similar concept and has claimed that the concept is derived from theology of Medieval and mentions it as follows: "a darkness carrying light, which is comparable with the unknowable God of theologies in medieval" (Cage, 2006, 23). In the research, the authors has called it as one element as a symbol of manifestation of the world of imagination in painting "lightness of night in paintings" (Eskandarpour Khorami and Shafiei, 2011, 26).
} 
In such proses, the symbolic language of painting has been always emphasized. In the study under the title of "vital values of Islamic Iranian painting", the author says: "in Iranian art before Islam, in the Zoroaster, the relationship of religion and art is tangible. Visual arts of that time were mainly designed based on symbolic concepts. Hence, art experts believe that symbolism is a gift from Iranians to all people" (Khazaei, 170). However, a ring is always missed for adjustment of the signified. This is same representational attitude analyzed be Derrida: "understanding the force based on forms; meaning considering it as something that could be understood in metaphorical illustration of structure means exactly failure in understanding it" (Sedgwick, 2009, 303). Nojumian AA has said in his study: according to structuralism and post-structuralism theories and especially deconstructionism, the game of inferences is not existed as the most important poststructuralist reading without language and prose. Hence, how a factor could be assumed in process of creating a prose that has no place in semiotic system of language? Imagination could be possible only when it is narrated. The question is that if the imagination needs no language, in which step it is changed into language with another system and sign like painting, music and so on? (Nojumian, 2005, 241242) and same question is considered here. If the world of imagination assumed beyond the material time and place is emerged using 2-D and color in painting, using which step and operations it takes this action? Whether it has any other instrument other than natural light and color? In rest of paper, Nojumian has referred to hostile position of De Man against the concept of "Symbol":

"Imagination is not independent from game of absence in prose. The language of metaphor and symbol referred in deconstruction can guarantee presence of meaning. It seems that the signifier and signified in metaphor and symbol are unit in their constant presence. De Man refers to allegory and metonymy instead. In the virtual languages, the distance and difference is considered that is not existed in symbol and metaphor. As a result, De Man has reversed the contrasts of metaphor and symbol on allegory and metonymy and has mentioned that imagination is also involved in same distances, absence and differences" (ibid, 243). On the contrary, in this study, the authors have claimed that the artist has emphasized the world of imagination, which is in consistence with the imagination of the artist and has gone away from the confused dreams and has illustrated the reality of the world of imagination (Eskandarpour Khorami and Shafiei, 2011, 24). It seems that two types of imagination are considered here: an imagination that is the factor to discover the real world and the imagination focused on the lower world: "if the nature of artist conducts the imagination 
toward lower world and the disobedient is dominated on the artist and the mortal and worldly glamor is dominated, the imagination of artist could have supervision on the world and the artist would fill the treasury by the tangible things and appearances; the illustrations in West become tangible and contain no deep meanings and include just physical beauty or the works contain no special thought and idea" (ibid, quoted from Rikhtegaran). Here, the main objective of the present study is presented. The main objective of this study is using the discussed language to evaluate the artistic traditions of west and east. However, let postpone this issue to the beginning of discussion about two other articles.

A question that is not answered in the said study is that how the 2-D could be assumed as the manifestation of heaven; although it seems that there is nothing in hand other than 2-D to imagine the heavens and explain that. Through careful investigation of the study, it could be found that discrimination of the claims, other than 2-3 items, is based on no case study and the explanations are also indirect and intangible in same 2-3 cases. At last, the authors have found that paining art has been aimed in symbolic expression of deep and internal holy concepts that are real. In general, it has been nlmentioned on this claim that absence of contrast, uniform and internal light, especially light of night in paintings and presence of light hollows in light of discrimination of high divine position could prove the claims of the author (ibid, 26). Certainly, such cases can't be a reason for claim of the author. The reason could be this issue that the discussion on contrast in painting, especially in relation to other elements, how could pave the way for the position of world of imagination; otherwise, how absence of contrast could be linked to imagination and supernatural nature of painting? Moreover, if this is true, the painting tradition with no contrast should be totally considered free from spiritual and supernatural concepts 9 . There is a huge gap for explanation of these claims in frame of sentences, which could remain unexplained based on same illusive features and the explicit issue to be proved. As a result, in such researches, literary language encompassed the whole study could conduct the theoretical discussion or logical discussion forming the paper to margins and some sentences like same statement are existed and the literary sentences seem meaningless in relation to heavy load of the sentences. More than everything, this point could

\footnotetext{
${ }^{9}$ John Cage says in his book: "since $13^{\text {th }}$ century, more traditional belief in God as light was dominated on wets theology. The light used to be considered as a martial phenomenon more than a supernatural phenomenon. Shadow was not suspected ethically and became important for painters in an increasing process. Among these painters, Massachusetts, masters of the early Renaissance, could change the story of Peter, who had the ability to heal the patients with his shadow, to one of the most effective parts of his murals" (Cage, 2006, 23). Here, 2 notes are existed: 1) presence of light as divine element in West painting tradition 2) presence of shadows as divine and healing element; it means that the western artist has been capable to consider shadow as a divine element based on personal beliefs and take its benefit in the paintings with such presumption.
} 
recall concept of sophistry considered by Derrida. Now, the main objective of this study about second and third articles criticized by this research is considered. The main objective in rest of the paper is the credit and reliability of using described language to evaluate stepwise tradition of art. The study "abstract logic in east and west painting space" in the generality of the paper has expressed its opinion on Western Art as follows: pre-modern art is such art that is totally realistic and free from supernatural and divine concept and modern artists have trend for abstract as an art that is basically absurdist and just with trend for innovations. The author of the article have counted three examples of ideas of Gustave Courbet about realism (the first) and Willem de Kooning and Paul Klee about abstraction (the second): "modernist and abstractive artist considering escaping from physical appearance as surrealist encounter and creation of magical spaces has been saturated by the destiny of humanist ideas of Greece and has achieved abstraction through deformation of natural structures and believes that the philosophy of the abstraction is in escaping from nature and believes that its law is defamiliarization [...]. However, eastern artist" sees the nature and understands the nature. However, while manifestation of artistic thoughts, the artist forgets the nature and becomes free from the material limitations and could show the work in ultimate novelty and innovation in an intuitive and supernatural approach (Ayatollahi and Hushyar, 2009, 54). Here, several points could be analyzed: 1) whether comprehensive division could be taken in size of east and west art and their properties could be counted using just several optional and case examples? In this regard, what is happened to western artists not encompassed in these examples? Let take an attractive statement of Goethe about French Painter, Claude Lorraine: "here, suddenly a perfect man is emerged, who feels beauty and has a world in his mind that could not be found out of it. Its pictures are real; although there is no effect of reality in the pictures. Claude Lorraine was familiar with the real world deeply and was also familiar with the smallest details, but he used to take its benefit just to express the world of his nice soul. This is real desire: using real ways and expressing it in such way that the expressed reality creates an illusion of the reality" (Qtd in Mannocci, 1988, 12).

Goethe has referred to reality of appearance of Claude Lorraine's paintings. He believes that Claude Lorraine is a paranoid painter, who takes benefit of poetic expression and presents it because of the extreme reality. Whether artists could not be found who have created another event in time period between ancient art and modern art of west in such tradition that watches itself in this way with the assumption that Greek art is realism? Maybe there are modern artists that their spiritual origin is there. 2) Is there any fundamental difference between the 
abstract called as "escape from nature" and the abstract that makes itself free from the material limitations and the nature and forgets it? This is an example of lingual games considered by this article: it is interpreted as escape once and has been interpreted as forgetting once again. If such differentiation is considered, could the abstract be divided to east and west abstract in all cases? Over the history, Iranian painting has shown no sign of style, personal attitude, individual expression and different and conflicting styles such as various isms and styles of west ${ }^{10}$ (Ayatollahi and Hushyar, 2009, 57). It seems that the author has no tendency to express this issue that all isms are in the form that are formed in modern art and they could only encompass small part of west art and they could not be compared as total west art with Iranian miniature or east art. It is mentioned in rest of this paper:

"It is right that studying the history of 2 recent decades of west art can prove this claim that the art is being deformed from surface to depth and from outside to inside; it should not be forgotten that abstract encounters caused by understanding the existential reality of nature, universe and spirituality of people that was neglected before this time in the Europe and the Western World has formed more than 2 thousand years cultural and artistic support of east" (ibid, 54). Independent from the criticism that the phrase "2 recent decades" could be used, it has been deducted here that pre-modern art of west was totally surface art, which its modern trend for abstract and depth is visual. Efforts to provide absolute definition of total concepts such as east and west art could make the scholars to complicate the huge part of history of art in a few-day board. It should be noted that the authors of this study have claimed finally that west and east are in heart of human and this is because, the human heart is the core and center for light; the light encompassing whole existence of human and as a origin of life of human being. As the east is sunk in light in the horizon, when human has been informed of his existential horizon and has understood it, he has achieved illumination (ibid, 59). An issue that is in fact independent from the main body of the paper considers totally the geographical differentiation of east and west art. Something that is analyzed here under the adjective "overall" is in fact description of the language that tries to cover the conflicting issues with assumptive attitude and tries to present a structural and integrated generality of a wide and various issues. This is same action taken by structuralism model before the history and the literature and philosophy. The third article is conducted under the title of "the similarities and differences of aesthetic foundations of styles and values in Islamic Iranian art and in West contemporary art" and the author has claimed in this study that:

\footnotetext{
${ }^{10}$ Judgment about this issue that to what extent the certainty of this sentence is rooted in the reality is assigned to the audiences and viewer.
} 
"In the current western society that art is based on art revival of $15^{\text {th }}$ century, nice perceptions and aesthetics are based on human-orientation criteria of Egypt, Greece and Ancient Rome that is same pure realism. However, at the contemporary east, especially in Iranian Art, perception of aesthetics is based on mythical and religious criteria and the realism has been replaced by imaginative manifestations of human and nature and the art of combination has become an effect of effects of God" (Ayatollahi, 35). In rest of same article, the author has claimed that to understand the aesthetic principles of a race, it is enough to refer to the source and origin of evolution of foundations of aesthetics of same race. In fact, the author considers west art totally as an art that is rooted in Egypt and Greece art and realism and humanorientation is its fundamental and unchangeable principle in it (ibid, 36). However, the author believes that since the time of Achaemenian, Iranian art has been based on principles that have been changed into the current form: "in ancient times in Iran, to be able to show the spiritual thoughts, the art has tried to go beyond the reality and leave the time and place as the elements of reality and real perceptions" (ibid, 37).now, it is reasonable to investigate the methods that the author of sais article believes that the eastern artist has selected to go beyond time and place ${ }^{11}$. The author has counted these elements as follows:

"1) Stay away from realism, 2. The focus of the combining elements around a central core 3) hatred of empty space 4) particle-orientation: it means that each element is formed of tiny and harmonized elements and is also coordinated to the scattered elements of empty spaces; 5) Induction of space and depth of space through showing combination elements from front, upper part and sides at the moment 6) Reliance on abstract objects and excellent and bright colors without mixing with black 7) differentiation of the world of painting and the real world" (ibid, 40).

Again, the question is that how these visual elements could be means for manifestation of issue without time and place and take people beyond the place and time? The presumption is that these elements are specified to Iranian painting; although it could be found through focusing on these elements that no one of them is specified to painting and these general foundations may be appeared in any part of history. Hence, the searching should be continued

\footnotetext{
${ }^{11}$ A note about this article and relevant articles is that in these proses, the artist is considered as the fruit of ruling ideology on the nation and the art of artist is nothing other than expression of principles of the rulers. When talking about Iranian art, Achaemenian and Sassaniads are considered and not the art of Achaemenid and Sassanid and when talking about western culture, the art is undisputed fruit of philosophy and special ideology that has been and is dominated on west culture. However, taking such attitude is certainly the simplest way for the person, who wants not to be involved in Conflicts and counterexamples, since if the individuality of artist is considered to the den government and ideology, different language and world is emerged, which is not involved in such generalization and using that to prove racial and ideological biases.
} 
to find case examples and elements: "colors are used uniformly, since Quran has emphasized uniformity of colors. Excellent colors are the effects of perfection and beauty of God" (ibid, 41). Is it right that consider imaginative art everywhere excellent colors are observed? If it is not true, what could make people consider art of a person such as Kandinsky just for eye enjoyment? According to Kandinsky, quoted by the author, "art was an ideal free from real forms and was just beautiful and eye catching and this was the fundamental principle of west art since before 1950"12 (ibid, 40).

In rest of paper, the author has mentioned that the technical foundations of aesthetics of Islamic art of east and west are same: "an artistic work is a collection of forms and colors combined in a pleasant order. How these elements should be combined, so that they could be pleasant in eyes of viewer and create pleasure could be considered as combination" (ibid, 42). It is continued: "however, the order, in which these elements are combined with each other, type of colors, different degrees of colors, concepts that could be transferred to audiences by them and other issues are different between east and west art" (ibid). The question is that is it true that these elements are combined with each other? ${ }^{13}$ It means that once the combination combining elements with each other is a universal issue and can be pleasant for the audiences and once again, the different of the combinations is that how same elements ${ }^{14}$ are combined with each other, so that it seems that unit elements are combined in two steps; at the first, the tendency is to create pleasant combination based on the producing foundations and once again, to meet the difference considered by the author. Finally, an example by the author is given: "for example, yellow color is color of disappointment in west and is the color for victory in Islamic art" (ibid, 42).

In field of explanation of differentiation of different combinations, the author has presented several examples and one of them is presented in short. It should be noted that what is questioned here and is rejected by the text is the claim of the text on sameness of imaginative foundations in its human scale.

In art of Far East, especially in Chinese art, the space (cosmic space) is the foundation for everything and human, living things, rocks, mountains, animals and plants are very small and insignificant compared to cosmos and cosmic space. Such thinking could make the Chinese

\footnotetext{
${ }^{12}$ To reject the theory, it is enough to have a general view to the Book "Spirituality in Art" by Kandinsky

${ }^{13}$ Reference to first quotation in this paragraph

14 Maybe the elements separated from the circle of universal foundations for this purpose, meaning some elements are not involved in combination; for example, it may be said that the form and color of the combination is made; although something that forms imaginative combination could be special tonalities of color and special forms; meaning explaining the concept of combination of color and form referred indirectly at the first and saying that the second combination is a different case; a case that is tangibly illogical and sophistry.
} 
artist try to imagine an infinite space in the landscapes and design and draw mountainous forest, long watershed and human being, tiny living things in depth of the forest (ibid, 42).

Whether combination of same elements is not combination of elements? If they have to follow special human foundations, hoe the criterion could be different? Whether a work can have two combinations?

\section{CONCLUSION}

After investigation of these cases and studying them in detail, it should be noted that deconstructive criticism tends to show that how the prose can cancel its own presumptions, claims and results. This is same action taken here due to the most fundamental issues considered in language of these articles. According to short reading of some parts of these articles, these issues could be summarized as follows: lack of explanation of manifestation of holy issue or divine example in painting works (the criterion as the main basis for fundamental differentiation of claims of east and west art and giving originality to one of them) whether in position of creation power of artist (Iranian painting artist has access to an original imagination) or in visual elements of image.

As it was observed, reliance on elements such as light and shadow, abstract and figure could not help considering the fundamental differentiation in research context and the differentiation is imposed by force on behalf of literary language on concepts in most cases.

The emphasis of these proses is on manifestation of imaginative issue in artistic works with reliance on the concept of "symbol". The symbol could omit the gap between imaginative and material object and coordinate them. Before this, a criticism of Paul De Man on concept was presented. In regard with conflict of metaphor and allegory (symbol and discourse), De Man explains that metaphor takes hidden effort to hide its textual functions. Finally, seductive power of metaphor could not hide the ways of array taking the power from them back (Norris, 2003, 102).

His reading for Niche repeats this issue several times that maybe Niche has neglected traditional idea (Rhetoric as eloquence) and has emphasized disclosure of function of arrays instead to show their prognostic and wrong claims. However, this needs a seductive representation method, which could hardly escape from the traps created by conscious selfcriticism. Niche's criticism about metaphysics, similar to Derrida's criticism, should be derived from a language that used both conceptual elements and persuasive elements. 
Rhetoric of such prose is belonged to both literature and philosophy to the extent that the differentiation is considered (ibid, 103).

Maybe one of the fundamental weaknesses of the desired language could be referred based on same attitude. These proses need an extremely proving and certain language and such a proof and certainty with outputs such as leaving a part of history and neglecting it and wrong definition of another tradition. Maybe through leaving the proving language, a prose could be created that uses allegorical and metaphorical language and removes veil of metaphorical issue and seems not unreasonable to this extent. Selden says in explanation of De Man: "De Man believes that some wrong readings are right and some others are not right. Wrong reading tries to consider wrong reading that is existed in all languages and tries not to suppress it" (Selden, 193).

The concept of imagination means a way to understand divine issues and if one tends to avoid generalization, it has deep roots at least in some part of culture, literature and art of west: "in imagination of romantic period, some superhuman and supernatural concepts were created". Says William Blake, the poet and painter of that time:

"Human perceptions are not limited to those things obtained from sensory organs. People understand something beyond the guess that could be obtained by the senses (even very strong senses). The enthusiasm and desire of human is infinite and the human is also infinite. Every person who observes infinity in all phenomena could also observe the God. Here, the imagination is the ability to have a vision and insight to the infinite world" (quoted from Nojumian, 237).

Fundamentally, if such attitude was not existed in west, critics such as De Man were not also existed in position of critic. If the infinite and superhuman issues escape from boundaries of language, time and place, its manifestation could not be limited to special structures in language in the research. As it was observed, it seems that there is no special instrument for this purpose. The question should be given that to what extent the differences between two cultures could be considered based on type of manifestation of non-lingual issue and beyond description? This issue could be understood based on evidences and non-lingual ways. Here, it should be noted that the aim is not to find similarity or comparison of two artistic traditions as a target. However, it could be mentioned that when language achieves such rules through counting the most surface differences, the difference could be rejected in its low level even through counting the most surface similarities. 


\section{REFERENCES}

1. Ayatollahi H, Hushyar, M, (2009), the logic of abstract in east and west paining space, Letter of Visual and Applied arts, Tehran

2. Ayatollahi, H. (2000), "similarities and differences of the principles of aesthetic styles and values in Iranian art Islamic and contemporary art of the West", the first Conference of painting the Muslim world: Saye Touba, Museum of Contemporary Art Tehran, Tehran

3. Otto, Rudolf (2001), the concept of the sacred, translation: Homayoun Hemmati, Naqsh-e Jahan, Tehran.

4. Eskandarpour Khorami, P. Shafiei F, (2011), "Iranian painting, manifestation of kingdom of imagination", College of Fine Arts in Visual Arts, number 48, Tehran.

5. Khazaei, M. (2000), "Iranian-Islamic painting eternal values" The First Conference of Islamic World Painting, Saye Touba, Museum of Contemporary Art, Tehran.

6. Sojudi, F. (2007), "The implication: from Saussure to Derrida" of Barthes and Derrida Seminar articles, penned by Dr. Amir Ali Nojumian, the Academy of Arts of the Islamic Republic of Iran, Tehran.

7. Sedgwick, Peter (2009), Descartes to Derrida review of European philosophy, translated by Mohammad Akhund-Zadeh, Ney Publishing, Tehran.

8. Zamiran, M. (2007), "and criticism of Derrida's approach to art," Journal of the Academy of Arts, No. 5, especially the art of deconstruction criticism, the Academy of Arts of the Islamic Republic of Iran, Tehran.

9. Nojoumian AA, (2007), "Derrida and the paradox of language literature" of Barthes and Derrida Seminar articles, penned by Dr. Amir Ali Nojoumian, the Academy of Arts of the Islamic Republic of Iran, Tehran.

10. Nojoumian AA, (2005), "deconstruction of Romantic imagination", proceedings of the First Seminar of Artistic Imagination, Edited by: Mansour Ahmadi, first edition, published by the Academy of Arts, Tehran.

11. Nozari, HA (2007), "deconstructive criticism in the field of art and aesthetics," Journal of the Academy of Arts, No. 5, especially the art of deconstruction criticism, the Academy of Arts of the Islamic Republic of Iran, Tehran.

12. Webster, Roger (2007), "Jacques Derrida and deconstruction of text", translation Abbas Barani, Arqanoon, No. 4, New Literary Review, Second Edition, the Ministry of Culture and Islamic Guidance, Tehran. 
13. Cage, John (2006), Color in Art, Thames \& Hudson Inc, London .

14. Derrida, Jacques, (2004), Difference, literary Theory: An Anthology, edited by Julie Rivkin and Michael Ryan, Blackwell Publishing Ltd, Oxford .

15. Derrida, Jacques, (2000), structure, sign and play in the discourse of the human sciences, Modern Criticism and Theory, Second Edition, Edited by David Lodge with Nigel Wood, Pearson Education, Inc, New York .

16. Mannocci, Lino, (1988), the Etchings of Claude Lorrain, Yale University

17. Norris, Christopher, (2003), Deconstruction, 3rd edition, Routledge, London and New York.

18. Rivkin, Julie, and Michael Ryan, Introduction: introductory Deconstruction, literary Theory: An Anthology, edited by Julie Rivkin and Michael Ryan, Blackwell Publishing Ltd, Oxford .

19. Selden, Raman, (1993), A Reader's guide to Contemporary Literary Theory, Peter Widdowson, Hertfordshire.

\section{How to cite this article:}

Jafarzadeh Z. Review a common approach in the analysis of iranian painting in reference to criticism of deconstruction. J. Fundam. Appl. Sci., 2017, 9(1S), 542-559. 